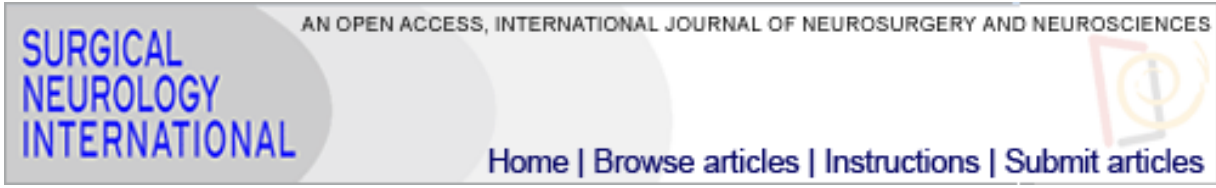

Surg Neurol Int. 2015; 6: 185.

PMCID: PMC4681126

Published online 2015 Dec 8. doi: 10.4103/2152-7806.171257

\title{
Surgical management of ruptured small cerebral aneurysm: Outcome and surgical notes
}

Giovanni Grasso $^{*}$ and Giancarlo Perra ${ }^{1}$

Department of Experimental Biomedicine and Clinical Neurosciences, Section of Neurosurgery, University of Palermo, Palermo, Italy

${ }^{1}$ Unit of Neurosurgery, A.R.N.A.S.Civico Hospital, Palermo, Italy

Giovanni Grasso: giovanni.grasso@unipa.it; Giancarlo Perra: perrag@gmail.com

* Corresponding author

Received 2015 Aug 11; Accepted 2015 Oct 23.

Coppyright : @ 2015 Surgical Neurology International

This is an open access article distributed under the terms of the Creative Commons Attribution-NonCommercial-ShareAlike 3.0 License, which allows others to remix, tweak, and build upon the work non-commercially, as long as the author is credited and the new creations are licensed under the identical terms.

\section{Abstract}

\section{Background:}

Management of small aneurysms often poses a therapeutic dilemma and surgical treatment or coiling can be considered as therapeutic choices. In the present study, we reviewed our series of ruptured small cerebral aneurysm treated surgically.

\section{Methods:}

A total of 53 consecutive patients with ruptured small aneurysm were surgically treated between January 2008 and July 2014. Data were retrospectively collected. Procedure-related death and complications were systematically reviewed. Clinical outcomes were assessed using the Modified Ranking Scale.

Neuroradiological follow-up was performed to assess aneurysmal occlusion and recanalization rate.

\section{Results:}

The mean aneurysm size was $2 \mathrm{~mm} \pm 0.8 \mathrm{~mm}$. All the patients were operated and the aneurysm clipped. Clinical outcomes were as expected on the basis of the presenting Hunt and Hess grade. Overall, major and minor neurological deficit related to clipping were $5.2 \%$ and $2.2 \%$, respectively. At the time of discharge, $84.9 \%$ of the patients presented with a favorable outcome, while $15.1 \%$ had poor clinical outcome. Aneurysm occlusion was achieved in all the cases. Neither recanalization nor re-aneurysmal rupture was observed in the clinical follow-up.

\section{Conclusion:}

Aneurysms, $3 \mathrm{~mm}$ in diameter or smaller, represent a therapeutic challenge. Given the proven role of microsurgery in small aneurysms and the perceived challenges with endovascular therapy, surgical clipping still can be considered an effective treatment modality in this setting. 
Keywords: Intracranial aneurysm, neuroradiology, retrospective studies, treatment outcome

\section{INTRODUCTION}

Subarachnoid hemorrhage (SAH) from rupture of an intracranial aneurysm is a devastating event. Data from population-based studies suggest that the incidence rates of cerebral aneurysm vary considerably

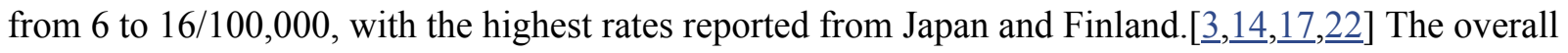
mortality rates from $32 \%$ to $67 \%$ with $10-20 \%$ of patients with long-term dependence due to brain damage. $[\underline{10}, \underline{13}]$ Twelve percent of patients affected by aneurismal SAH die before medical treatment and $25 \%$ die within 24 h.[4] A further 40-60\% mortality rate occurs within 30 days.[4]

Outcome depends on a myriad of interrelated factors, including the severity of the initial event, rebleeding, perioperative medical management, and the timing and technical success of aneurysm treatment.

Treatment of ruptured cerebral aneurysm is the primary concern in all patients after SAH. To date, surgical management is related to a mortality rate of $2 \%$ and approximately $10 \%$ morbidity rate. $[1,21, \underline{29}]$ Main complications related to surgery are bleeding occurrence before, after, or during surgical clipping as a result of an intra-operative rupture (IOR), cerebral ischemia induced by temporary clip positioning or of parent vessel occlusion, and brain damage related to intraoperative retractors use.[ㅁ, $\underline{6}, \underline{7}, \underline{9}]$

Small aneurysms account for $6 \%$ of all ruptured intracranial aneurysms[28] and their management remains challenging. The International Study of Unruptured Intracranial Aneurysms (ISUIA)[30] concluded that asymptomatic aneurysms $<7 \mathrm{~mm}$ in diameter in the anterior circulation have a minimal provability of rupture. Most recently, the Unruptured Cerebral Aneurysm Study (UCAS) yielded results similar to the ISUIA.[25] However, several investigators have contradicted these studies, reporting a higher percentage of small aneurysms among their case series of ruptured intracranial aneurysms. $[\underline{16}, \underline{27}, \underline{31}]$ This indicates a discrepancy between the ISUIA and UCAS data and the size of ruptured aneurysms seen in routine clinical practice.

Although the International Subarachnoid Aneurysm Trial (ISAT) showed an outcome benefit with endovascular coiling compared to surgical clipping,[19] treatment of small aneurysms have not been considered given the technical problem for the endovascular approach. Coiling of small aneurysms is associated with a relatively high risk of iatrogenic aneurysm rupture or migration of the coil into the parent vessel.[20] The purposes of our study were to evaluate safety of clipping procedure for small-ruptured aneurysms in terms of morbidity, mortality and efficiency of aneurysm occlusion, recurrence and rebleeding at short- and long-term follow-up.

\section{METHODS}

A retrospective chart review was performed of all patients who had surgical treatment of an aneurysm $\leq 3$ $\mathrm{mm}$ in diameter between 2008 and 2014. Among a cohort of 382 surgically treated aneurysms, a total of 53 consecutive patients were enrolled. Blister aneurysms were not considered in this series since they differ both morphologically and histologically from saccular aneurysms and likely represent a distinct pathophysiology. Medical charts, angiographic studies, magnetic resonance imaging (MRI) scans, computed tomographic (CT) and CT angiography (CTA) scans were carefully reviewed. Patients' age, sex, Hunt and Hess grades, and aneurysm locations were recorded. All diagnoses were confirmed on imaging (CTA, MRI angiography and/or digital angiography). Morbidity and mortality related to clipping were defined as intra-procedural and/or postoperative ischemic or bleeding events. Stroke was defined as a new neurological deficit on clinical examination during $48 \mathrm{~h}$ following surgery with a visualization of CT hypodensity and/or high signal MRI intensity on apparent diffusion coefficient sequences. Patients presenting with neurological deficits without modified signal or density in neuroradiological exams were 
considered affected by cerebral vasospasm. Bleeding complications were defined as a new postoperative hematoma in the aneurysmal vascular area or an increasing volume of more than one-third of an intraparenchymal hematoma in the next $12 \mathrm{~h}$ after surgery. An independent neuroradiologist and neurosurgeon, blinded to the study, revised both clinical and radiological records to evaluate causes for ischemic or bleeding events and their correlation with surgery.

Procedural complications, epidural/subdural hematomas, infections, and postoperative seizures, were also included. Clinical outcomes were measured with the Modified Rankin Scale and radiological follow-up by CTA to assess aneurysmal occlusion and recanalization rate.

\section{Surgical technique}

Surgical treatment was undertaken following the diagnosis of cerebral aneurysm, and no later than $24 \mathrm{~h}$ following bleeding. Different surgical approaches were used according to aneurysm location. Following the intraoperative identification of the aneurysm, temporary clips were routinely used in all the cases to prevent aneurysm rupture. Accordingly, aneurysm was isolated and clipped using miniclip. Lamina terminalis was fenestrated in all the cases for hydrocephalus prevention.[24] At the end of the procedure, patients were monitored in the Neuro Intensive Care Unit and nimodipine was administered for cerebral vasospasm. Patients returned to neurosurgical unit and discharged to home or rehabilitation facility according to their functional disabilities.

\section{RESULTS}

\section{Patient population}

Between January 2008 and July 2014, among a cohort of 382 surgically treated aneurysms, 53 consecutive patients underwent surgical treatment for ruptured small cerebral aneurysm. The mean age of patients was 50.4 years (range, $23-77$ years). Seventy percent of patients were women $(n=37)$ and $30 \%$ were men $(n=$ 16). The mean Hunt and Hess grade at the time of admission was 2 (range, 2-4) and the mean Fisher score was 2 (range, 1-4). The mean aneurysm size was $2 \mathrm{~mm} \pm 0.8 \mathrm{~mm}$. Demographics characteristics and aneurysm location are showed in Table 1.

Aneurysm clipping was successfully achieved in all the patients.

\section{Outcome}

Ischemia related to surgery was observed in $15 \%$ of the cases and hemorrhage in $13.2 \%$. No mortality related to clipping was observed. Overall, major and minor neurological deficit related to clipping were $5.2 \%$ and $2.2 \%$, respectively. IOR rate was $15 \%$ in the whole cohort. In one case (1.9\%), a surgical site infection was observed and completely solved by targeted antibiotic therapy. In another case $(1.9 \%)$, postoperative seizure was treated by a combination of antiepileptic drugs. Cerebral vasospasm was observed in $32 \%$ of the cases. Hydrocephalus developed in $15 \%$ of the patients and was treated by ventriculoperitoneal shunt placement. At the time of discharge, $84.9 \%$ of the patients attained a favorable outcome (moderate, mild, or no disability). Only 8 patients (15.1\%) had poor clinical outcome. Overall, Hunt and Hess Grades III-V were associated with poor clinical outcome [Table 2]. During the follow-up, only 35 patients among 53 patients $(66 \%)$ received a CTA control to assess recanalization rate. Complete aneurysm occlusion was observed in all the patients at an average neuroradiological follow-up spanning 52 months. Neither recanalization nor rebleeding was reported for patients who have been controlled by a second CTA.

\section{Illustrative case}


This 55-year-old man suffered sudden-onset headache. On admission, he manifested no neurological deficits. Brain CT scan demonstrated SAH involving the basal and interhemispheric cisterns with a Fisher Grade 2 [igure 1a]. CTA revealed an aneurysm at the right carotid bifurcation [iigure 1b]. A Hunt and Hess Grade 2 was assigned.

Surgical treatment was undertaken via right pterional approach. The aneurysm was identified on the carotid bifurcation [igire 2a]. Temporary clips were applied to avoid aneurysm rupture [igure 2b]. The aneurysm was well dissected from the clot and arachnoid adherence. A mini straight clip was applied and the aneurysm excluded from the cerebral circulation [Figure 2c] .

The patient did not present any postoperative neurological deficit and was discharged on postoperative day 5.

\section{DISCUSSION}

Small aneurysms with $3 \mathrm{~mm}$ or less in diameter are rare lesions representing a real challenge for diagnosis and management. Because of their small size, fragile-thin wall, and a broad-based neck, these aneurysms are difficult to manage. The optimal management of small aneurysms remains controversial. In the ISUIA, the perioperative morbidity and mortality for patients who underwent either clipping or coiling of their unruptured intracranial aneurysm was about $10 \% .[12,15]$ The natural history of these aneurysms remains unpredictable with the potential to increase in size, change in configuration, and rebleeding rate that seems to be uncertain compared to larger aneurysms.[28]

It has been reported that patients with ruptured intracranial aneurysms $<5 \mathrm{~mm}$ are associated with a higher rate of presentation with poor Hunt and Hess grades than ruptured intracranial aneurysms larger than 5 $\mathrm{mm}$.[] ] Moreover, in the clinical setting, approximately, half of the ruptured intracranial aneurysms $<5 \mathrm{~mm}$ and $65 \%$ of ruptured intracranial aneurysms larger than $5 \mathrm{~mm}$ are clinically presented with a good Hunt and Hess SAH grade.[]]

Endovascular management is technically challenging because of the small size of the aneurysms. Coiling has been associated with an increased risk of intraprocedural rupture.[르, 20] It has been reported as successful treatment by using covered stent grafts or multiple porous stents.[11] More recently, flowdiverting stents have been proposed as a treatment modality for these aneurysms.[23] However, also with these technique, pitfalls have been reported to cause stroke as the result of occlusion of jailed perforating vessels.[므]

Since patients with small aneurysms were excluded from ISAT, information about these aneurysms comes from unpowered studies. The BRAT, another leading study, reported poor outcome at 1 year in $33.7 \%$ of patients treated with open surgery versus $23.2 \%$ of those who underwent endovascular treatment.[18] However, also in this study, the investigators did not specify how many small aneurysms were enrolled, how they were treated, or what the outcome was in such patients. The study from Chalouhi et al.[్] is the first that directly compared surgical clipping and endovascular therapy in a consecutive series of patients harboring small ruptured cerebral aneurysms. They found that endovascular therapy had a significantly lower complication rate than open surgery, with a low incidence of intraprocedural rupture. Favorable outcomes were not statistically different between the endovascular and surgical groups. Endovascular procedures failed in up to $10 \%$ of all cases in that study, with a significant proportion of patients' crossing over to surgical clipping. The rate of recurrence was $18.2 \%$ and retreatment was $12.7 \%$. Surgical clipping of small-ruptured aneurysm was associated with a $23.3 \%$ complication rate and permanent morbidity and mortality rates limited to $8.3 \%$ and $0 \%$, respectively.

In our study, aneurysm clipping was successfully achieved in all the patients. Major and minor 
neurological deficit related to clipping were $5.2 \%$ and $2.2 \%$, respectively. No mortality related to clipping was observed. Ischemia related to surgery was observed in $15 \%$ of the cases and hemorrhage in $13.2 \%$. Overall, IOR rate was $15 \%$ in the whole cohort. Cerebral vasospasm was observed in $32 \%$ of the cases. Hydrocephalus developed in $15 \%$ of the patients and was treated by ventriculoperitoneal shunt placement. At the time of discharge, $84.9 \%$ of the patients attained a favorable outcome (moderate, mild, or no disability). Only 8 patients (15.1\%) had poor clinical outcome. Overall, Hunt and Hess Grades III-V were associated with poor clinical outcome.

During the follow-up, complete aneurysm occlusion was observed in all the patients at an average neuroradiological follow-up of 52 months. Neither recanalization nor rebleeding was reported for patients who have been controlled by a second CTA. In one case, a surgical site infection was observed and completely solved by targeted antibiotic therapy. In another case, postoperative seizure was treated by a combination of antiepileptic drugs.

In our series, we routinely used temporary clips for safe aneurysm dissection. Small aneurysms have a fragile, thin wall and dissection may be followed by aneurysm rupture leaving a hole into the artery wall. Temporary clips application reduces the risk of aneurysm rupture and gives an optimal view for miniclip application on aneurysm.

Our findings suggest that surgical clipping can still be considered an effective treatment modality for small-ruptured aneurysm. However, this study is based on a retrospective analysis from a single center experience without independent outcome assignment and do not compare surgical versus endovascular treatment. Furthermore, a significant number of clipped aneurysms have not been controlled by second CTA. These limitations, however, do not detract from the importance of the results obtained. Aneurysm clipping was successfully achieved in all the patients without mortality and low morbidity rate related to surgical treatment. At the time of discharge, almost all the patients attained a favorable outcome.

\section{CONCLUSION}

Small aneurysms represent a true challenge for diagnosis and management. Our findings support the effectiveness of surgical clipping although emerging data points out a blossoming endovascular solution. Large randomized controlled trial to compare the two treatment modalities can clarify most of the important issues. In the meantime, surgical treatment of small aneurysms remains safely and effectively.

\section{Financial support and sponsorship}

Nil.

\section{Conflicts of interest}

There are no conflicts of interest.

\section{Acknowledgments}

We thank Prof. J. Hernesniemi, from the Helsinki University, for his valuable suggestions and for providing the surgical images.

\section{Footnotes}

http://surgicalneurologyint.com/Surgical-management-of-ruptured-small-cerebral-aneurysm:-Outcome-and-surgicalnotes/

\section{REFERENCES}


1. Bekelis K, Missios S, MacKenzie TA, Desai A, Fischer A, Labropoulos N, et al. Predicting inpatient complications from cerebral aneurysm clipping: The nationwide inpatient sample 2005-2009. J Neurosurg. 2014;120:591-8. [PubMed: 24032701]

2. Brinjikji W, Lanzino G, Cloft HJ, Rabinstein A, Kallmes DF. Endovascular treatment of very small (3 $\mathrm{mm}$ or smaller) intracranial aneurysms: Report of a consecutive series and a meta-analysis. Stroke. 2010;41:116-21. [PubMed: 19926837]

3. Broderick JP, Brott T, Tomsick T, Huster G, Miller R. The risk of subarachnoid and intracerebral hemorrhages in blacks as compared with whites. N Engl J Med. 1992;326:733-6. [PubMed: 1738378]

4. Broderick JP, Brott TG, Duldner JE, Tomsick T, Leach A. Initial and recurrent bleeding are the major causes of death following subarachnoid hemorrhage. Stroke. 1994;25:1342-7. [PubMed: 8023347]

5. Chalouhi N, Penn DL, Tjoumakaris S, Jabbour P, Gonzalez LF, Starke RM, et al. Treatment of small ruptured intracranial aneurysms: Comparison of surgical and endovascular options. J Am Heart Assoc. 2012;1:e02865. [PMCID: PMC3487356] [PubMed: 23130171]

6. Choi SW, Ahn JS, Park JC, Kwon do H, Kwun BD, Kim CJ. Surgical treatment of unruptured intracranial middle cerebral artery aneurysms: Angiographic and clinical outcomes in 143 aneurysms. J Cerebrovasc Endovasc Neurosurg. 2012;14:289-94. [PMCID: PMC3543914] [PubMed: 23346544]

7. Davies JM, Lawton MT. Advances in open microsurgery for cerebral aneurysms. Neurosurgery. 2014;74(Suppl 1):S7-16. [PubMed: 24402495]

8. Dolati P, Pittman D, Morrish WF, Wong J, Sutherland GR. The frequency of subarachnoid hemorrhage from very small cerebral aneurysms ( $<5 \mathrm{~mm})$ : A population-based study. Cureus. 2015;7:e279. [PMCID: PMC4494560] [PubMed: 26180703]

9. Flamm ES, Grigorian AA, Marcovici A. Multifactorial analysis of surgical outcome in patients with unruptured middle cerebral artery aneurysms. Ann Surg. 2000;232:570-5. [PMCID: PMC1421189] [PubMed: 10998655]

10. Grasso G. An overview of new pharmacological treatments for cerebrovascular dysfunction after experimental subarachnoid hemorrhage. Brain Res Brain Res Rev. 2004;44:49-63. [PubMed: 14739002]

11. Henkes H, Reinartz J, Preiss H, Miloslavski E, Kirsch M, Kühne D. Endovascular treatment of small intracranial aneurysms: Three alternatives to coil occlusion. Minim Invasive Neurosurg. 2006;49:65-9. [PubMed: 16708333]

12. Hijdra A, Braakman R, van Gijn J, Vermeulen M, van Crevel H. Aneurysmal subarachnoid hemorrhage. Complications and outcome in a hospital population. Stroke. 1987;18:1061-7. [PubMed: 3686578]

13. Hop JW, Rinkel GJ, Algra A, van Gijn J. Case-fatality rates and functional outcome after subarachnoid hemorrhage: A systematic review. Stroke. 1997;28:660-4. [PubMed: 9056628]

14. Ingall T, Asplund K, Mähönen M, Bonita R. A multinational comparison of subarachnoid hemorrhage epidemiology in the WHO MONICA stroke study. Stroke. 2000;31:1054-61. [PubMed: 10797165]

15. Joo SW, Lee SI, Noh SJ, Jeong YG, Kim MS, Jeong YT. What is the significance of a large number of ruptured aneurysms smaller than $7 \mathrm{~mm}$ in diameter? J Korean Neurosurg Soc. 2009;45:85-9.

[PMCID: PMC2651552] [PubMed: 19274117]

16. Juvela S, Poussa K, Lehto H, Porras M. Natural history of unruptured intracranial aneurysms: A long- 
term follow-up study. Stroke. 2013;44:2414-21. [PubMed: 23868274]

17. Kiyohara Y, Ueda K, Hasuo Y, Wada J, Kawano H, Kato I, et al. Incidence and prognosis of subarachnoid hemorrhage in a Japanese rural community. Stroke. 1989;20:1150-5. [PubMed: 2772975]

18. McDougall CG, Spetzler RF, Zabramski JM, Partovi S, Hills NK, Nakaji P, et al. The barrow ruptured aneurysm trial. J Neurosurg. 2012;116:135-44. [PubMed: 22054213]

19. Molyneux A, Kerr R, Stratton I, Sandercock P, Clarke M, Shrimpton J, et al. International subarachnoid aneurysm trial (ISAT) of neurosurgical clipping versus endovascular coiling in 2143 patients with ruptured intracranial aneurysms: A randomised trial. Lancet. 2002;360:1267-74. [PubMed: 12414200]

20. Nguyen TN, Raymond J, Guilbert F, Roy D, Bérubé MD, Mahmoud M, et al. Association of endovascular therapy of very small ruptured aneurysms with higher rates of procedure-related rupture. $\mathrm{J}$ Neurosurg. 2008;108:1088-92. [PubMed: 18518708]

21. Proust F, Gérardin E, Chazal J. Unruptured intracranial aneurysm and microsurgical exclusion: The need of a randomized study of surgery versus natural history. J Neuroradiol. 2008;35:109-15.

[PubMed: 18417219]

22. Sarti C, Tuomilehto J, Salomaa V, Sivenius J, Kaarsalo E, Narva EV, et al. Epidemiology of subarachnoid hemorrhage in Finland from 1983 to 1985. Stroke. 1991;22:848-53. [PubMed: 1853404]

23. Szikora I, Berentei Z, Kulcsar Z, Marosfoi M, Vajda ZS, Lee W, et al. Treatment of intracranial aneurysms by functional reconstruction of the parent artery: The Budapest experience with the pipeline embolization device. AJNR Am J Neuroradiol. 2010;31:1139-47. [PubMed: 20150304]

24. Tomasello F, d'Avella D, de Divitiis O. Does lamina terminalis fenestration reduce the incidence of chronic hydrocephalus after subarachnoid hemorrhage? Neurosurgery. 1999;45:827-31.

[PubMed: 10515477]

25. UCAS Japan Investigators, Morita A, Kirino T, Hashi K, Aoki N, Fukuhara S, et al. The natural course of unruptured cerebral aneurysms in a Japanese cohort. N Engl J Med. 2012;366:2474-82.

[PubMed: 22738097]

26. van Rooij WJ, Keeren GJ, Peluso JP, Sluzewski M. Clinical and angiographic results of coiling of 196 very small $(<$ or $=3 \mathrm{~mm}$ ) intracranial aneurysms. AJNR Am J Neuroradiol. 2009;30:835-9.

[PubMed: 19131407]

27. Wardlaw JM, White PM. The detection and management of unruptured intracranial aneurysms. Brain. 2000;123(Pt 2):205-21. [PubMed: 10648430]

28. Weir B, Disney L, Karrison T. Sizes of ruptured and unruptured aneurysms in relation to their sites and the ages of patients. J Neurosurg. 2002;96:64-70. [PubMed: 11794606]

29. Wermer MJ, van der Schaaf IC, Algra A, Rinkel GJ. Risk of rupture of unruptured intracranial aneurysms in relation to patient and aneurysm characteristics: An updated meta-analysis. Stroke. 2007;38:1404-10. [PubMed: 17332442]

30. Wiebers DO, Whisnant JP, Huston J, 3rd, Meissner I, Brown RD, Jr, Piepgras DG, et al. Unruptured intracranial aneurysms: Natural history, clinical outcome, and risks of surgical and endovascular treatment. Lancet. 2003;362:103-10. [PubMed: 12867109]

31. Winn HR, Jane JA, Sr, Taylor J, Kaiser D, Britz GW. Prevalence of asymptomatic incidental aneurysms: Review of 4568 arteriograms. J Neurosurg. 2002;96:43-9. [PubMed: 11794602] 
Figures and Tables

Table 1

\begin{tabular}{lc}
\hline Demographics characteristics & 53 \\
Total patients $(n)$ & $50.4 \pm 10.1$ \\
Mean age (year, & \\
mean \pm SD) & 16 \\
Male & 37 \\
Female & $2 \pm 1.2$ \\
Hunt and Hess (mean $\pm S D$ ) & $2 \pm 1.1$ \\
Fisher (mean \pm SD) & $2 \pm 0.8$ \\
Aneurysm size (mean $\pm S D)$ & \\
Aneurysm location & 18 \\
Anterior communicating & 12 \\
Carotid terminus & 10 \\
Posterior communicating & 6 \\
Anterior choroidal & 3 \\
Pericallosal & 2 \\
PICA & 2 \\
Basilar & 53 \\
Total
\end{tabular}

SD: Standard deviation, PICA: Posterior inferior cerebellar artery

Demographics characteristics and aneurysm location

Table 2

Total aneurysms

Favorable outcome (\%)

Poor clinical outcome (\%)

Ischemia related to surgery (\%)

Hemorrhage related to

surgery $(\%)$

Major neurological deficit (\%)

Minor neurological deficit (\%)

Cerebral vasospasm (\%)

Hydrocephalus (\%)

Outcome related to surgery

Figure 1 


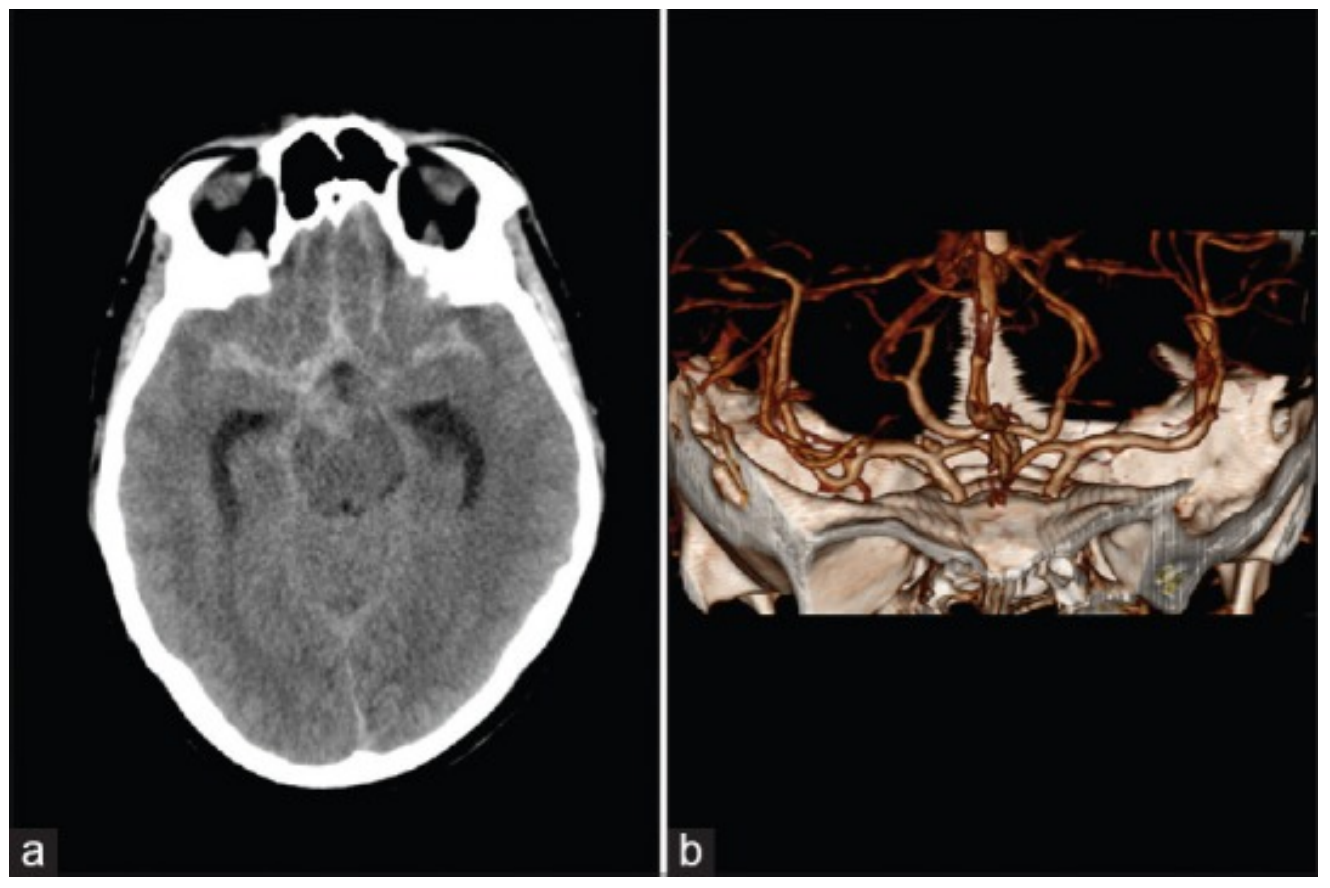

(a) Brain computed tomographic scan showing a Fisher 2 subarachnoid hemorrhage; (b) computed tomographic angiography revealing a small aneurysm at the right carotid bifurcation

Figure 2

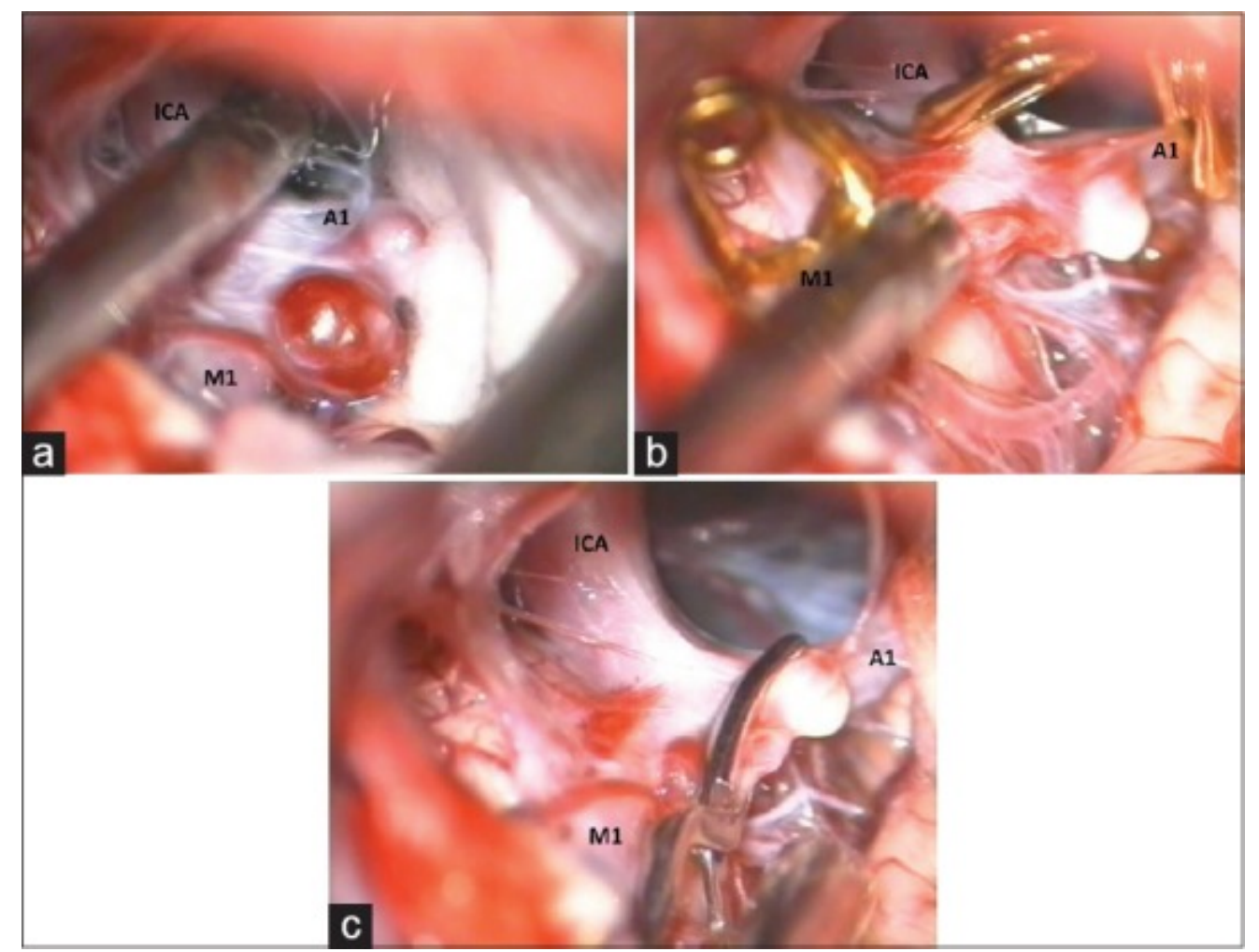

Intraoperative images showing the key steps for aneurysm clipping. (a) Small aneurysm on the right carotid bifurcation; (b) positioning of a temporary clip on the right internal carotid artery, A1 segment of the right anterior cerebral artery, and M1 segment of the right middle cerebral artery; (c) aneurysm closure by miniclip application

Articles from Surgical Neurology International are provided here courtesy of Medknow Publications 